\title{
ALTITUDE E TEMPERATURA: ESTUDO DO GRADIENTE TÉRMICO NO RIO GRANDE DO SUL
}

\author{
FRITZSONS, Elenice - elenice.fritzsons@embrapa.br \\ Engenheira Florestal - Doutora - Pesquisadora da Embrapa Florestas \\ WREGE, Marcos Silveira - marcos.wreve@embrapa.br \\ Doutor em Agrometeorologia - Pesquisador da Embrapa Florestas
}

MANTOVANI, Luiz Eduardo - lem@ufpr.br

Doutor - Professor Departamento de Geologia da Universidade Federal do Paraná

\begin{abstract}
RESUMO: A relação da altitude com a temperatura assume especial importância para as regiões tropicais e subtropicais, pois diferenças de algumas centenas de metros de altitude podem significar mudanças sensíveis no ambiente, na adaptação da biota e sucesso do cultivo agrícola. A temperatura do ar sofre alterações com a altitude, latitude e longitude, em geral, nesta ordem de importância. Em função do relevo e do posicionamento geográfico, cada local apresenta um gradiente térmico vertical médio específico. Neste trabalho, o estado do Rio Grande do Sul foi dividido em grupos climáticos homogêneos, pela análise de agrupamento, e foram compostas análises de correlação entre a temperatura média das quatro estações do ano e média anual, com as respectivas altitudes das estações meteorológicas dos grupos. Foram utilizadas 36 estações meteorológicas. A correlação da altitude com a temperatura média anual do verão foi mais forte comparada à temperatura média do inverno. Para os coeficientes de correlação mais elevados, foram obtidas retas de regressão linear simples e os respectivos coeficientes de determinação das retas. 0 gradiente térmico médio obtido para o conjunto de todas as estações meteorológicas foi de, aproximadamente, $0,75^{\circ} \mathrm{C}$ a cada 100 metros de altitude e para o grupo das estações meteorológicas presentes na Serra do Nordeste do estado foi de $0,9^{\circ} \mathrm{C}$.
\end{abstract}

PALAVRAS-CHAVE: clima, gradiente térmico, análise de agrupamento, clima do sul da América do Sul.

ALTITUDE AND TEMPERATURE: STUDY OF THE THERMAL GRADIENT IN THE STATE OF RIO GRANDE DO SUL

ABSTRACT: Altitude and temperature relationships are especially important for the tropical and subtropical regions, where an altitudinal increase of some hundred meters changes the environmental conditions and leads to sensitive adaptation of the biota and this is very important for cultivation. Average air temperature changes with altitude, latitude and longitude and also each location, have his specific thermal gradients related to these parameters. In this work, the State of Rio Grande do Sul was delimited in homogeneous climate subregions and analyses were made of correlation between average annual temperature and in each climatic seasons with their altitudes of groups formed. The correlation between altitude and average summer temperature, considering 36 meteorological stations, was in general, stronger than that for July. For the higher correlation coefficients were obtained straight lines and their coefficients of determination with simple linear regression. The average thermal gradient obtained for the set of all stations of the state, was $0,75^{\circ} \mathrm{C}$ per each $100 \mathrm{~m}$ high and for northeast center was $0,9^{\circ} \mathrm{C}$ per each $100 \mathrm{~m}$ high.

KEYWORDS: climate, thermal gradient, cluster analysis, south America climate. 


\section{INTRODUÇÃO}

Os biomas existentes na Terra têm estreita relação com o clima, principalmente com a temperatura e a pluviosidade. O estado do Rio Grande do Sul é o segundo maior estado da região Sul-Sudeste cobrindo uma área de $281.730 \mathrm{~km}^{2}$. De acordo com a classificação climática de Köppen (1931), o clima é mesotérmico úmido - Cf, incluindo dois subtipos, Cfa e Cfb. A variedade "Cfa" apresenta a temperatura do mês mais quente superior à "Cfb", que se restringe ao planalto basáltico superior e ao escudo Sul-Rio-Grandense, enquanto a "Cfa" pertence às demais áreas do estado. Rossato (2011) desenvolveu um estudo mais detalhado do clima do Rio Grande do Sul e o colocou em "Área de domínio de Clima subtropical", subdividido em quatro tipos, sendo que esta divisão foi baseada em umidade e diferença das temperaturas no inverno e verão, considerando também a amplitude longitudinal do estado.

Em termos globais, a temperatura se altera em função da latitude, longitude e altitude e, em temos microclimáticos, da exposição das encostas ao sol, ao vento, da proximidade de áreas alagadas, marítimas, etc. A relação da altitude com a temperatura é especialmente importante para as regiões tropicais e subtropicais, onde um desnível de algumas centenas de metros de altitude pode provocar mudanças sensíveis no clima, na formação dos solos e, consequentemente, na adaptação das espécies animais e vegetais e na aptidão para vários sistemas de uso da terra.

Deve ser lembrado que tanto altitude, longitude e latitude apesar de não constituírem diretamente parâmetros climáticos, têm influência sobre fatores não totalmente descritos apenas pelos dados de temperatura e pluviometria. Altitude influi no tipo de insolação, amplitude térmica diária, incidência de geadas, probabilidade de granizo, ocorrência de ventos fortes. Longitude aqui corresponde a continentalidade e controla fatores tais como incidência de brisa marinha, que chega a exercer influência bem além de uma centena de quilômetros nos relevos baixos dos pampas, causando quedas de temperatura e aumento de umidade em tardes de primavera e verão, o que reduz a amplitude térmica diária. Latitude se vincula diretamente a duração do fotoperíodo ao longo do ano e no Rio Grande do Sul ao aumento da amplitude térmica anual, as maiores do Brasil.

O clima no Rio Grande do Sul é influenciado pelas condições de relevo, pela latitude, altitude e distância do mar, sendo que o relevo é composto por serras, planaltos, depressões e vasta planície costeira. O relevo gaúcho, de forma geral, é o menos pronunciado entre os estados do Sul e Sudeste; as elevações máximas não ultrapassam 1400 m de altitude contra mais de $1800 \mathrm{~m}$ no Paraná e Santa Catarina e mais de $2700 \mathrm{~m}$ em todos os estados do Sudeste. As temperaturas médias são mais elevadas no Litoral Norte, Depressão Central e Fronteira Oeste com a Argentina, onde existe a calha do Uruguai. Nas regiões de maior altitude, como o Planalto Nordeste, predominam temperaturas mais baixas. 
Os sistemas ditos polares são os grandes dinamizadores do clima no Rio Grande do Sul, mas fatores geográficos locais também interferem (ROSSATO, 2011), sendo o relevo o principal (WOLLMANN \& GALVANI, 2012). Em relação aos demais estados brasileiros ele se diferencia pela incidência maior de correntes de circulação do vento em superfície do quadrante oeste, isto embora os alísios de quadrante leste sejam ainda predominantes conforme se entende a partir de estudos detalhados (GOVERNO DO ESTADO DO RIO GRANDE DO SUL, 2014).

A temperatura do ar normalmente decresce com a elevação da altitude numa proporção de, aproximadamente, $1^{\circ} \mathrm{C} / 100 \mathrm{~m}$ (gradiente adiabático existente quando o ar é seco). Esta taxa de arrefecimento ocorre, pois uma massa de ar seco em ascensão está sujeita a pressões atmosféricas cada vez menores, expandindo seu volume e diminuindo a temperatura, isto é, transformando energia térmica em energia potencial. No entanto como o gradiente térmico depende da saturação do ar, na média, o decréscimo da temperatura do ar com a altitude em geral se situa em torno de $1^{\circ} \mathrm{C}$ a cada 180 metros (DURY, 1972).

Nesse trabalho, utilizou-se a série de dados climáticos do Rio Grande do Sul com o objetivo de determinar, por meio de equações de regressão linear, as alterações da temperatura em função da altitude, a fim de definir um gradiente térmico vertical médio para todo o Estado do Rio Grande do Sul e por regiões homogêneas de temperatura, a exemplo de trabalhos desenvolvidos por OLIVEIRA NETO et al., 2002; MEDEIROS et al., 2005; CARGNELUTTI et al., 2006; DIEDRICH et al., 2007. Além disso, agruparam-se as estações semelhantes quanto a temperatura média anual e temperaturas das estações do ano.

\section{MATERIAL E MÉTODOS}

Foram utilizados os dados climáticos de 36 estações meteorológicas publicados em Wrege et al. (2011) para o estado do Rio Grande do Sul, que se referem ao período de observação de 1976-2005. Os dados foram submetidos à análise de agrupamento. Para isto foram utilizados os valores das temperaturas médias das quatro estações do ano (primavera, verão, outono e inverno), altitude e, ainda, a latitude e longitude, convertidas em graus decimais para cada estação.

A análise de agrupamento foi escolhida por ser eficiente para reunir indivíduos com características semelhantes, sendo que inúmeros trabalhos que envolvem informações ambientais têm sido realizados desta forma (FRITZSONS et al., 2008; 2011, 2011a; CHIERICE ; LANDIM, 2014, KELLER FILHO et al., 2005; WREGE et al., 1997; EVERRITT, 1993). É fundamental que, na análise de agrupamento, seja definida uma medida de similaridade ou de distância entre os grupos a serem formados (KELLER FILHO et al., 2005; EVERITT, 1993). Neste caso, foi escolhida a medida métrica Euclidiana, uma vez que as variáveis classificatórias selecionadas são medidas reais. A escolha do número de grupos a serem usados baseou-se na análise gráfica do 'Dendrograma' e no gráfico 'Distância de Aglomeração'. 
Depois dos grupos formados, foi feita a análise de variância com a temperatura média anual para verificar a diferença entre os grupos. Após, foi uma análise de correlação entre a altitude das estações meteorológicas e as temperaturas médias sazonais e a temperatura média anual para o conjunto das estações e para cada grupo formado.

Para os coeficientes de correlação de maiores magnitudes foram obtidas retas de regressão e os respectivos coeficientes de determinação das retas $\left(r^{2}\right)$. O gradiente térmico foi composto para o verão, a exemplo do trabalho de Fritzsons et al. (2008) feito para o estado do Paraná, que utilizou a temperatura média do mês de janeiro com êxito.

\section{RESULTADOS}

Há forte variabilidade das condições climáticas distribuídas num intervalo de 0 a $1050 \mathrm{~m}$ de altitude (Tabela 1 ).

Tabela 1. Sumário estatístico das temperaturas médias (em ${ }^{\circ} \mathrm{C}$ ) das estações meteorológicas e altitude (em metros).

\begin{tabular}{lllllll}
\hline & Altitude & Primavera & Verão & Outono & Inverno & Anual \\
\hline Média & 345 & 18,0 & 22,9 & 18,6 & 13,7 & 18,3 \\
\hline Valor mínimo & 2 & 14,3 & 18,3 & 15,1 & 10,8 & 14,7 \\
\hline Valor máximo & 1048 & 20,9 & 25,8 & 20,9 & 16,0 & 20,8 \\
\hline Amplitude térmica & 1046 & 6,6 & 7,5 & 5,8 & 5,2 & 6,1 \\
\hline
\end{tabular}

Esta variabilidade foi observada no dendrograma resultante da aplicação da análise de agrupamento, onde se verificou a formação de dois grandes grupos naturais: as áreas com temperaturas mais baixas e altitudes elevadas (Grupo B) e as outras áreas do estado (Grupo A). O grupo A, composto por grande parte das estações, foi ainda subdividido em três grupos (A1 e A21 e A22) (Figura 1).

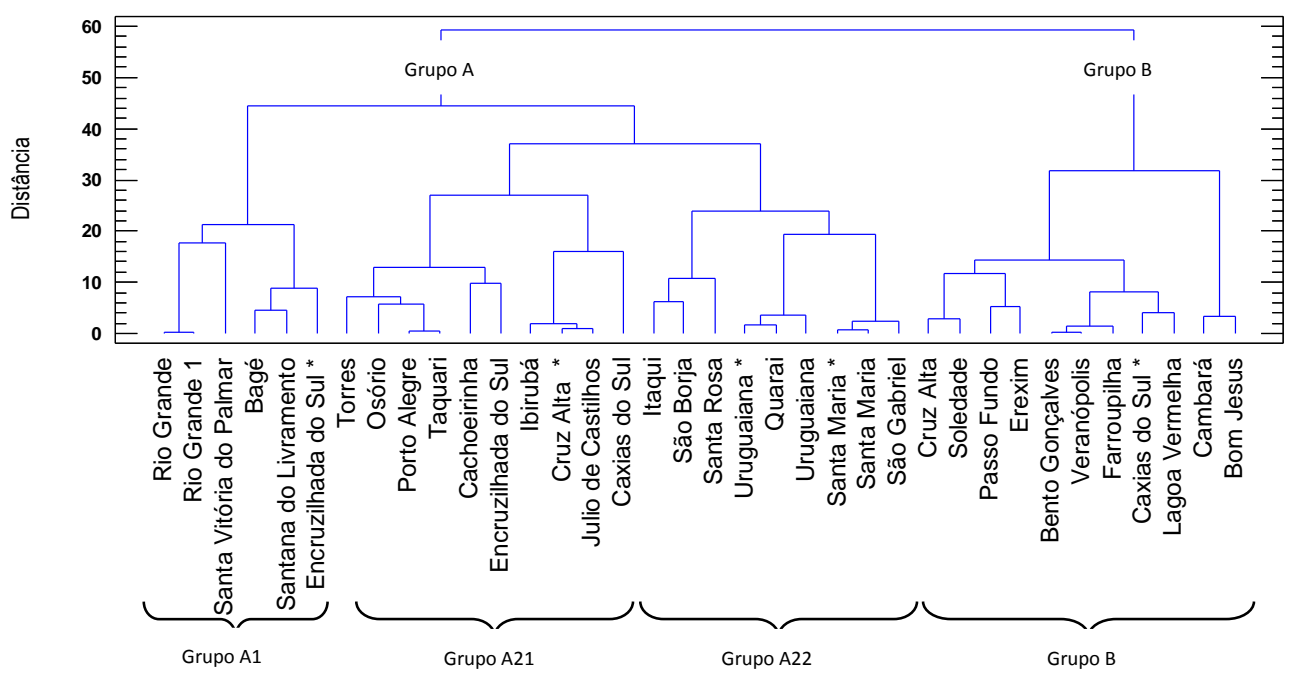

Figura 1. Dendrograma com os grupos formados pela análise de agrupamento 
$\mathrm{Na}$ análise de variância (Tabela 2) feita para os quatro grupos composta a partir da temperatura média, o valor $f$ foi de 29,82 e o valor $p$ menor que 0,05, o que evidencia que os grupos são diferentes.

Tabela 2. ANOVA para temperatura media anual com os 4 grupos

\begin{tabular}{l|l|l|l|l|l}
\hline Fonte & Soma dos quadrados & $\mathrm{Df}$ & Quadrado médio & Razão $F$ & Valor $p$ \\
\hline Entre grupos & 51,8171 & 3 & 17,2724 & 29,82 & 0,0000 \\
\hline Dentro dos grupos & 18,5369 & 32 & 0,57928 & & \\
\hline Total & 70,3541 & 35 & & & \\
\hline
\end{tabular}

No gráfico de médias (Figura 2) pode-se verificar que as médias não são sobrepostas e que o grupo $\mathrm{B}$ apresenta as menores médias.

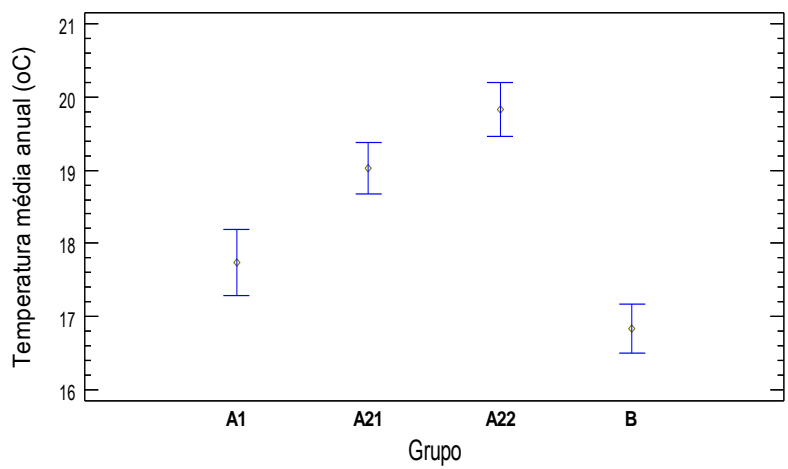

Figura 2. Gráfico de médias para os quarto grupos formados

Desta forma, o grupo A1 é formado por seis estações meteorológicas, presentes nos seguintes municípios: Rio Grande (duas estações), Santa Vitória do Palmar, Bagé, Santana do Livramento e Encruzilhada do Sul. (Figura 4). O grupo A21 é formado por dez estações que se encontram de forma mais dispersa em regiões com altitudes variáveis, entre $5 \mathrm{~m}$ (Torres - Litoral Norte) a 410 m (Encruzilhada do Sul - estação de maior elevação da Serra do Sudeste). Este grupo está localizado, em grande parte, na porção centro leste e no Litoral Norte do Estado. O Grupo A22 há 9 estações meteorológicas localizadas na Fronteira Oeste, presentes nos municípios de: Santa Rosa, São Borja, Itaqui, Uruguaiana duas estações), Quarai, São Gabriel e Santa Maria.

Já o Grupo B é composto por 11 estações meteorológicas que estão localizadas, em sua grande maioria, nas regiões Noroeste e Nordeste do estado, em áreas serranas do Planalto Norte Rio Grandense. As altitudes variam entre $430 \mathrm{~m}$ em Cruz Alta até $1048 \mathrm{~m}$ em Bom Jesus. 


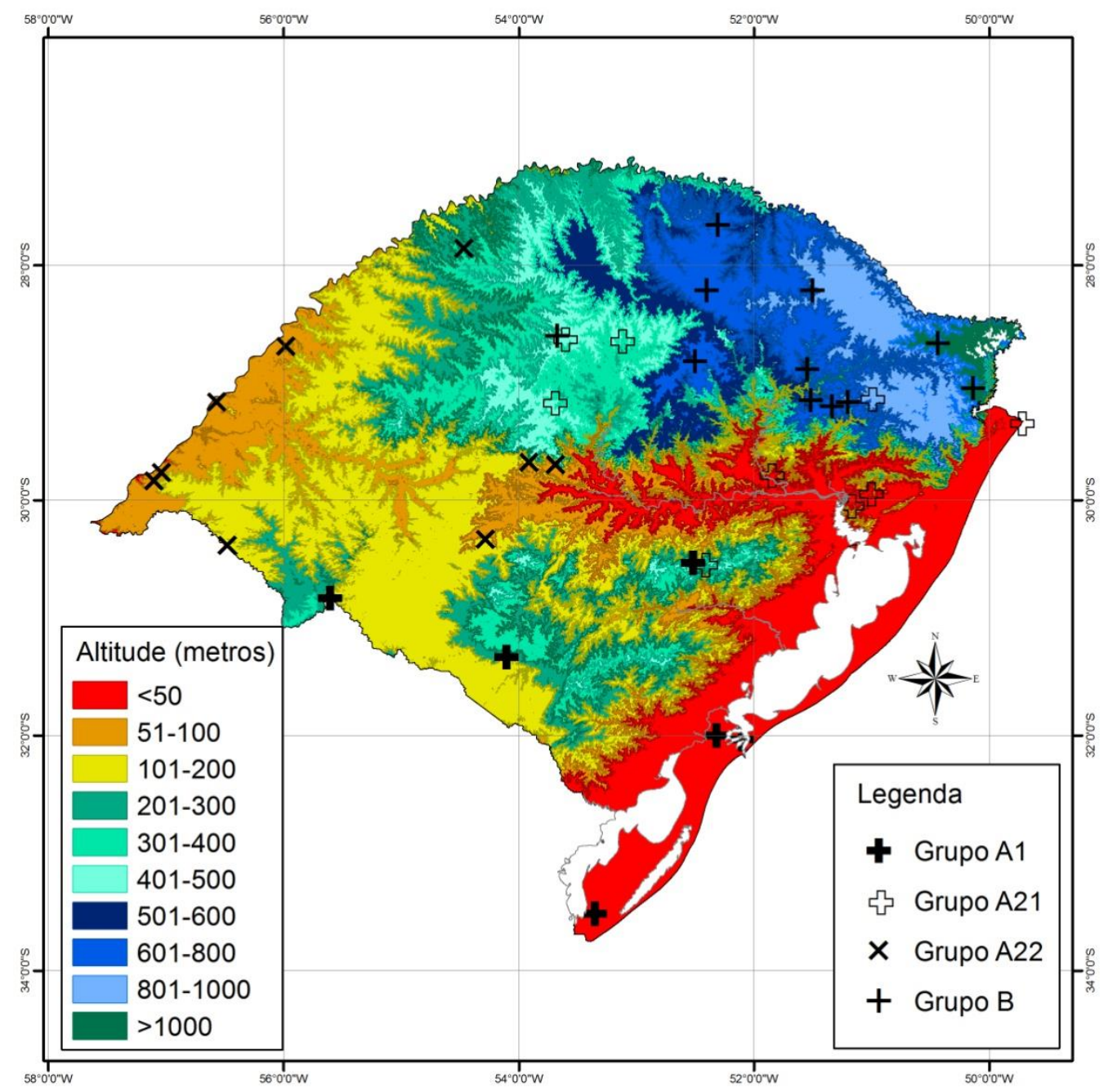

Figura 3. Mapa hipsométrico com a localização dos grupos $A 1, A 21, A 22$ e $B$

Quanto à interação entre altitude e temperatura, não houve correlação entre as temperaturas (média das estações do ano e média anual) e altitude para os grupos $A$ ( $A 1, A 21$ e A22), mas houve para o grupo $B$ e também quando foi considerado o conjunto de todas as estações meteorológicas (Tabela 3). 
Tabela 3. Correlação (Pearson) entre altitude e temperaturas (média anual, média de verão, de outono e de inverno) do conjunto de todas as estações meteorológicas e as do grupo B.

\begin{tabular}{l|l|l|l|l|l|l}
\hline Estações & Média & Primavera & Verão & Outono & Inverno & $\mathrm{n}^{\circ}$ de estações \\
meteorológicas & anual & & & & & \\
Todas & $-0,68$ & $-0,62$ & $-0,75$ & $-0,72$ & $-0,51$ & 34 \\
Grupo B & $-0,70$ & $-0,66$ & $-0,74$ & $-0,71$ & $-0,69$ & 11 \\
\hline
\end{tabular}

Nota: $n$ - número de grupos; todos os valores $p$ da correlação de Pearson ficaram abaixo de 0,05 , o que indica que os valores de correlação encontrados são significativamente diferentes a um nível de confiança de $95 \%$.

Assim:

1. Quando se analisa todas as estações meteorológicas há uma correlação negativa moderada (Tabela 4) da altitude com a temperatura média anual, com as temperaturas do inverno e primavera e uma correlação forte com o outono e verão;

2. Para o grupo $B$, que agrupa as estações meteorológicas com temperaturas mais baixas, há uma correlação negativa moderada com as temperaturas do inverno e primavera e uma correlação forte com a média anual, com o verão e com outono.

Tabela 4. Interpretação do coeficiente de correlação

\begin{tabular}{ll}
\hline Valor de correlação & Nível de correlação \\
\hline 0 a 0,19 & Bem fraca \\
\hline 0,2 a 0,39 & Fraca \\
\hline 0,4 a 0,69 & Moderada \\
\hline 0,7 a 0,89 & Forte \\
\hline 0,9 a 1,0 & Muito forte \\
\hline
\end{tabular}

Fonte: Shimakura (2006)

Como resultado da análise de regressão entre altitude e temperatura média do verão, quando foram utilizados os dados de todas as estações meteorológicas, o coeficiente de determinação foi de 0,56\% (Tabela 5), o que significa que $56 \%$ da variação de temperatura deve ser atribuído a altitude. Considerando apenas as estações do grupo B, o coeficiente de determinação da reta é parecido, mas deve-se considerar que há menor número de pontos. Não foram efetuadas as análises de regressão para os outros grupos devido à baixa correlação entre altitude e temperatura.

Tabela 5. Alteração da temperatura (em ${ }^{\circ} \mathrm{C}$ ) a cada $100 \mathrm{~m}$ de altitude, para a rede de estações meteorológicas do Rio Grande do Sul (temperaturas do verão)

\begin{tabular}{l|l|l|l|l|l|l}
$\begin{array}{l}\text { Estações } \\
\text { meteorológicas }\end{array}$ & $\mathrm{X}=1$ & $\mathrm{X}=2$ & Gradiente & $\begin{array}{l}\text { Alteração } \\
\left({ }^{\circ} \mathrm{C} / 100 \mathrm{~m}\right)\end{array}$ & $\begin{array}{l}\mathrm{N}^{\circ} \text { de estações } \\
\text { meteorológicas }\end{array}$ & $\begin{array}{l}\text { Coeficiente de } \\
\text { determinação }\end{array}$ \\
\hline Todas & 3250,27 & 3118,14 & 132,13 & 0,76 & 36 & 0,56 \\
\hline grupo B & 2476.24 & 2365,68 & 110,56 & 0.90 & 11 & 0,55
\end{tabular}


Interpretando a equação da reta composta para a temperatura média do verão para todas as estações seria atingida, hipoteticamente, em média, aos 3.071 metros (Figura 4).

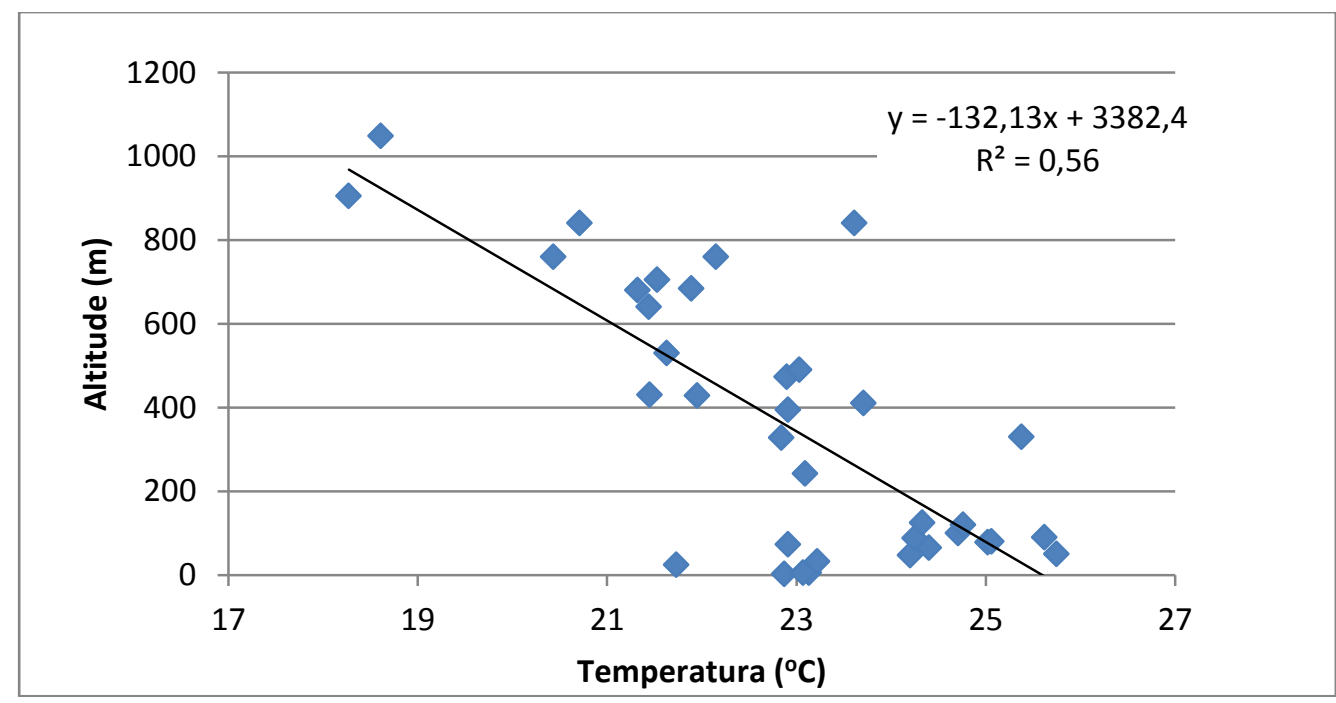

Figura 4. Alteração da temperatura média do ar no verão em função da altitude considerando todas as estações

\section{DISCUSSÃo}

Neste trabalho o estado foi dividido em quatro grupos diferentes: $A 1$, A11, A21 e B. O Grupo A1 é formado pelas estações presentes na porção de Sul do estado gaúcho nos extremos, próximas à fronteira com o Uruguai. Neste agrupamento, as temperaturas são relativamente baixas devido às latitudes maiores e pela entrada de frentes frias. No verão, as temperaturas são elevadas e a duração do dia mais alongada. A altitude varia pouco, entre $2 \mathrm{~m}$, em Rio Grande (Litoral Sul), até 328 metros, em Santana do Livramento (fronteira com o Uruguai).

Nos grupos A21 e A22 estão agrupadas as estações com os maiores valores de temperatura, compreendendo zonas de baixa altitude, de modo geral, como o Litoral Norte, a Depressão Central e a Fronteira Oeste, principalmente na calha do Uruguai. O grupo A21 é formado por estações localizadas, em grande parte, nas porções Centro Leste e no Litoral Norte do Estado. As estações do grupo A22, que apresentam as médias anuais mais elevadas, observado no gráfico de médias (Figura 2), estão na Fronteira Oeste, presentes nos municípios: Santa Rosa, São Borja, Itaqui, Uruguaiana duas estações, Quarai, São Gabriel e Santa Maria. 
O Grupo B, agrega as estações com os menores valores de temperatura no Estado, devido à altitude, representando a região Serrana do Nordeste. As temperaturas são baixas, principalmente no outono-inverno, mas também não se elevam muito no verão, como ocorre no grupo $A$.

Os grupos visualizados no dendrograma são realmente grupos distintos, como observado na ANOVA (Tabela 2), ou seja, há maior amplitude de variação entre os grupos do que dentro de um grupo.

A correlação entre altitude e temperatura do ar é mais forte no verão, considerando todas as estações e as estações do grupo B. Isto confirma o observado por Ferreira et al. (1971) que afirmaram que por meio de equações de regressão utilizando a latitude e altitude poderia se estimar a temperatura média de um local, e que a temperatura sofria maior influencia da altitude nos meses de verão e outono em relação aos meses de inverno e primavera.

Deve se considerar que no outono-inverno ocorrem inversões térmicas, que contribuem para que a temperatura do ar, nos vales, permaneça mais fria por maior tempo. Desta forma, as menores temperaturas distribuem-se melhor no espaço geográfico e as regiões de maior altitude não se diferenciam tanto das outras regiões, contribuindo para a ocorrência de temperaturas mais homogêneas. Além disso, nesta época do ano, os raios solares têm maior ângulo de incidência sobre a Terra, aumentando as diferenças de temperatura do ar nas faces de exposição do terreno. As vertentes "face Norte" recebem maior insolação enquanto nas expostas ao Sul a insolação é menor e a exposição aos ventos mais frios, vindos de quadrante meridional é maior.

Para os grupos A1, A21 e A22 a correlação da temperatura com o relevo foi baixa, porque as variações de temperatura que ocorrem não têm relação com a altitude, uma vez que as mesmas não são elevadas. Para o grupo das estações A21, as quais provavelmente sofrem influencia oceânica, Ferreira et al. (1971) afirmaram que a temperatura média mensal não poderia ser estimada diretamente pela altitude.

Para o estado do Rio Grande do Sul, como um todo, obteve-se a variação de $0,76{ }^{\circ} \mathrm{C} / 100 \mathrm{~m}$ para os meses de verão, mas com baixo coeficiente de determinação $(0,56)$. Para as estações meteorológicas do grupo B o gradiente foi de $0,90{ }^{\circ} \mathrm{C} / 100 \mathrm{~m}$ (coeficiente de determinação de 0,55 ). Como um dado mais geral, Ometto (1981) cita a alteração de 0,6 ${ }^{\circ} \mathrm{C}$ para cada $100 \mathrm{~m}$ de altitude. Bardin et al. (2010) encontraram para uma região do estado de São Paulo, considerando as temperaturas máximas, um coeficiente variando entre 0,8 e $1,0^{\circ} \mathrm{C}$ e, para mínimas, entre 0,6 e $0,8^{\circ} \mathrm{C}$.

No Paraná, o valor de 0,5 ㄷ para cada $100 \mathrm{~m}$ de altitude foi obtido por Maack (1981) no estado do Paraná, entretanto para o mesmo estado utilizando uma série de dados mais recente e método semelhante ao utilizado neste trabalho, Fritzsons et al. (2008) obtiveram, para o mês de janeiro, $0,72^{\circ} \mathrm{C}$ /100m como um valor médio para todas as estações meteorológicas, sendo que o gradiente variou entre 0,71 a $0,79{ }^{\circ} \mathrm{C} / 100 \mathrm{~m}$ para as diferentes regiões. 
Sendo assim, o gradiente térmico vertical médio obtido para o conjunto de todas as estações meteorológicas para o verão é muito próximo do obtido para o Paraná, embora quando se considera as estações meteorológicas localizadas nas áreas de altitudes mais elevadas, como as do grupo $B$, este valor fique bem acima do calculado, em geral, para todo o Paraná.

Um aspecto que deve ser observado é que quando se tomam estações próximas pertencentes a uma mesma situação climática o desnível altimétrico é o que exerce maior influência na diferenciação das temperaturas. Ao contrario quando as distâncias aumentam e fatores tais como latitude, longitude, situação geoclimática mudam, a análise estatística pode mostrar uma diluição da influência das altitudes devida à concorrência destes demais fatores.

\section{CONCLUSÕES}

Considerando um conjunto de 36 estações meteorológicas, há uma correlação forte entre a altitude e a temperatura média de verão e outono e correlação moderada para a primavera e para a média anual. Quando se consideram apenas as estações meteorológicas que pertencem ao grupo das estações de temperaturas mais baixas (Grupo B), a correlação é forte para todas as estações do verão, do outono e média anual.

Para o grupo de estações meteorológicas dos locais com menores variações altitude no Rio Grande do Sul, não houve correlação entre altitude e temperatura devido às altitudes serem menores e associado à interferência de outros fatores: latitude, longitude, situação topográfica, incidência ou não da brisa do mar, dentre outros.

O gradiente térmico vertical médio para os meses de verão, obtido para o conjunto de todas as estações meteorológicas do Estado, foi de $132,13 \mathrm{~m}$, ou seja, há uma diminuição média de $1^{\circ} \mathrm{C}$ a cada 132 metros de ascensão vertical. Isto equivale a $0,75^{\circ} \mathrm{C}$ a cada 100 metros de altitude. Este valor foi obtido a partir de uma reta de regressão com um coeficiente de determinação de 0,56\%. Para o grupo das estações meteorológicas com menores valores de temperatura, situada na região serrana do nordeste do estado, o gradiente obtido foi de $0,90^{\circ} \mathrm{C}$ a cada 100 metros de altitude.

O método utilizado para desenvolver este trabalho separando as estações meteorológicas no Estado do Rio Grande do Sul em grupos climáticos, verificando a existência dos distintos grupos pela ANOVA e em seguida compor a análise de correlação e as equações de regressão para cada grupo, mostrou-se eficiente para atingir os objetivos propostos. No entanto, de posse de um maior número de estações, os grupos formados podem ser subdivididos e, desta forma, abranger uma maior detalhamento do clima no que se refere às temperaturas do estado. 


\section{REFERÊNCIAS BIBLIOGRÁFICAS}

BARDIN, Ludmila; PEDRO JUNIOR, Mário J.; MORAES, Jener F. L. de. Estimativa das temperaturas máximas e mínimas do ar para a região do Circuito das Frutas, SP. Revista Brasileira de Engenharia Agrícola e Ambiental, Campina Grande, v. 14, n. 6, 2010.

CARGNELUTTI FILHO, A.; MALUF, J. R. T; MATZENAUER, R.; STOLZ, Á. P. Altitude e coordenadas geográficas na estimativa da temperatura mínima média decendial do ar no Estado do Rio Grande do Sul. Pesquisa Agropecuária Brasileira, Brasília, v. 41, n. 6, p. 893-901, 2006.

CHIERICE Natale; LANDIM JÚNIOR, Paulo Milton Barbosa. Análise de Chuva e vazão na bacia hidrográfica do rio Pardo. São Paulo, UNESP, Geociências, v. 33, n. 2, p.244 -260, 2014.

DIEDRICH, V. L., FERREIRA, E. R, ECKHARD, R.R. Espacialização das estimativas das temperaturas mínimas, médias e mínimas anuais para o Vale do Taquari - RS - Brasil, pelo método de regressão linear. Anais. XIII Simpósio Brasileiro de Sensoriamento Remoto, Florianópolis, Brasil, 21-26, INPE, p. 153159. 2007.

DURY, G. H. High temperature extremes in Austrália. Anais. Annals of the Association of American Geographers. 62 (3), 388-400. 1972.

EVERRITT, B.S. Cluster Analysis. 3nd ed. London: Heinemann Educational Books, 1993. 122 p.

FERREIRA, M.; BURIOL, G.A.; ESTEFANEL, V.; PINTO, H.S. Estimativa das temperaturas médias mensais e anuais do Estado do Rio Grande do Sul. Revista do Centro de Ciências Rurais, v.1, p.21-52, 1971.

FRITZSONS, E.; MANTOVANI, L. E.; AGUIAR, A. V. de. Relação entre altitude e temperatura: uma contribuição ao zoneamento climático no Estado do Paraná. Revista de Estudos Ambientais, v. 10, n. 1, p. 49-64, 2008.

FRITZSONS, E.; MANTOVANI, L. E.; WREGE, M. S.; CHAVES NETO, A. Análise da pluviometria para definição de zonas homogêneas no Estado do Paraná. Ra'ega: O Espaço Geográfico em Análise, Curitiba, v. 23, p. 555-572, 2011.

FRITZSONS, E.; BOGNOLA, I. A.; MANTOVANI, L. E. ; WREGE, M. S.; CARVALHO JUNIOR, W. de; CHAGAS, C. da S. Carta de unidades edafoclimáticas para o Estado do Paraná para plantios florestais. Colombo: Embrapa Florestas, 2011a. 24 p. (Embrapa Florestas. Documentos, 223).

GOVERNO DO ESTADO DO RIO GRANDE DO SUL. Atlas Eólico do Rio Grande do Sul. 2014. Disponível em: https://dl.dropboxusercontent.com/u/25365701/Atlas_Eolico_Rio\%20Grande_do_Sul_201 4.pdf. Data da disponibilidade: 20/01/2014 
KELLER, T.; ASSAD, E.D.; LIMA, P.S. de R. Regiões pluviometricamente homogêneas no Brasil. Pesquisa Agropecuária Brasileira, v.40, n.4, p.311322, 2005.

KÖPPEN, W. Climatología: con un estudio de los climas de La Tierra. México: Fondo de Cultura Económica. 1948. 478p.

MAACK, R. Geografia física do Estado do Paraná. Rio de Janeiro: Livraria José Olympio Ed., 1981. 442p.

MEDEIROS, S.S.; CECILIO, R.A.; MELO JÚNIOR, J.C.F.; SILVA JUNIOR, J.L.C. Estimativa e espacialização das temperaturas do ar mínimas e máximas na região nordeste do Brasil. Revista Brasileira de Engenharia Agrícola e Ambiental, v. 9, p. 247 - 255. 2005.

OLIVEIRA NETO, S.N. de; REIS, G.G. dos; REIS, M. das G.F.; LEITE, H.G.; COSTA, J.M.N. da. Estimativa de temperaturas mínima, média e máxima do território brasileiro situado entre 16 e 240 latitude sul e 48 e $60^{\circ}$ longitude oeste. Engenharia na Agricultura, v.10, p.8-17, 2002.

OMETTO. J. C. Bioclimatologia vegetal. São Paulo: Ed. Agronômica Ceres. 1981. 129-132 p.

ROSSATO, M. S. (2011). Os climas do Rio Grande do Sul : variabilidade, tendências e tipologia. Tese (Doutorado em geografia da Universidade Federal do Rio Grande do Sul. Instituto de Geociências). Universidade Federal do Rio Grande do Sul. Porto Alegre, 2011.

SHIMAKURA, S. E. Interpretação do coeficiente de correlação. 2006. Disponível em http://leg.ufpr.br/ silvia/CE003/node74.html. Data da disponibilidade: $25 / 01 / 2014$

WOLLMANN, C. A; Galvani, E. Caracterização climática do Rio Grande do Sul: dos estudos estáticos ao entendimento da gênese. In: Revista Brasileira de Climatologia, vol 11, p. 87-103. 2012.

WREGE, M. S.; GONÇALVES, S. L.; CARAMORI, P. H.; VASCONCELLOS, M. E. C.; OLIVEIRA, D. de; ABUCARUB NETO, M.; CAVIGLIONE, J. H. Risco de deficiência hídrica na cultura do feijoeiro durante a safra das águas no Estado do Paraná. Revista Brasileira de Agrometeorologia, Santa Maria, v. 5, n.1, p. 51-59, 1997.

WREGE, M. S.; STEINMETZ, S.; GARRASTAZU, M. C.; REISSER JR, C.; ALMEIDA, I. R. de ; HERTER, F. G.; CARAMORI, P. H.; RADIN, B. ; MATZENAUER, R.; BRAGA, H. J.; PRESTES, S. D. ; CUNHA, G. R. da ; MALUF, J. R. T.; PANDOLFO, C. Atlas Climático da Região Sul do Brasil: Estados do Paraná, Santa Catarina e Rio Grande do Sul. 1. ed. Pelotas: Embrapa Clima Temperado, 2011. v. 1. 332p. 